\title{
SIMULASI SPRINGBACK BENCHMARK PROBLEM CROSS MEMBER NUMISHEET 2005
}

\author{
Akhmad Arif Wahyudi, Waluyo Adi S., Tri Widodo B.R. \\ Jurusan Teknik Mesin Fakultas Teknik Universitas Muhammadiyah Surakarta \\ Jl. A. Yani Pabelan Kartasura Tromol Pos 1 Sukoharjo \\ E-mail: abatran@plasa.com
}

\begin{abstract}
ABSTRAK
Numisheet 2005 merupakan suatu konferensi internasional yang membahas tentang perubahan konsep dan teknologi baru pada lingkup simulasi sheet metal forming, konsep dan teknologi baru tersebut dimasudkan untuk memenuhi kebutuhan semua industri metal forming. Untuk memenuhi kebutuhan para desainer dan juga ilmu pengetahuan, konferensi menentukan tiga permasalahan yang lebih dikenal dengan BENCHMARK PROBLEM, yaitu Benchmark I, Benchmark II, dan Benchmark III. Benchmark problem ini dimaksudkan agar designer dapat mengevaluasi model pada proses sheet metal forming dengan melakukan pengujian eksperimental maupun simulasi model.Penelitian tugas akhir ini bertujuan untuk menganalisis komponen cross member benchmark II Numisheet 2005 dengan menggunakan metode simulasi numerik. Untuk keperluan proses simulasi numerik pada komponen cross member digunakan File Nas dari 2 jenis file yang tersedia pada benchmark II numisheet 2005 yaitu IGES File dan NAS File.Proses penelitian dan simulasi numerik komponen cross member ini menggunakan solver ABAQUS V64 PR11 dengan bantuan solver MSC. PATRAN dengan prosedur mengikuti guidelines numisheet 2005.Springback selalu terjadi pada sheet metal forming untuk itu perlu diperhatikan karena pengaruhnya sangat penting terhadap perubahan bentuk dan ukuran pada produk akhir yang dihasilkan. Perolehan informasi tentang springback digunakan untuk mendesain dies serta mengontrol ketelitian pada saat memproses bentuk komponen dan memprediksi kegagalan pada proses stamping yang dilakukan.
\end{abstract}

Kata kunci : Numisheet 2005, Abaqus 6.4, Simulasi, Springback.

\section{PENDAHULUAN}

Pada penelitian ini, dengan mengaplikasikan teknologi CAD/CAM pada aplikasi software atau dalam istilah teknik disebut dengan solver berbasis Metode Elemen Hingga non linear untuk simulasi sheet metal forming.

Pada kasus ini dengan bantuan solver ABAQUS dapat dilihat secara visual proses simulasi springback dan forming dan juga ditampilkan besarnya tegangan, regangan, gaya, displacement dan lain-lain yang terjadi lewat kontur-kontur warna yang ditampilkan, sehingga dapat diprediksi bagian-bagian kritis atau bagian yang berpotensi mengalami kerusakan. Penggunaan FEA/FEM pada proses simulasi numerik komponen cross member dengan bantuan program ABAQUS untuk menghasilkan gambaran pada komponen cross member problem benchmark II Numisheet 2005 seperti yang terlihat pada gambar1. 


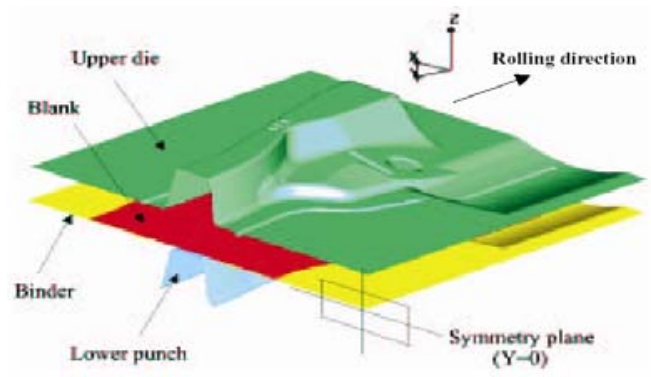

\section{Gambar 1. Komponen cross member problem benchmark II Numisheet 2005}

Prosedur penelitian ini adalah sebagai berikut :

1. Data komponen cross member benchmark II mengikuti guidelines numisheet 2005.

2. Untuk proses simulasi numerik, penulis memanfaatkan solver ABAQUS, dengan berdasarkan pada Analysis model yang di impor dari file nastran cross member benchmark II Numisheet 2005 melalui bantuan solver MSC. PATRAN.

Perhatian penelitian ini diutamakan pada simulasi springback melalui proses drawing pembentukan pelat mengikuti desain dies yang telah ditentukan sehingga terbentuk komponen cross member.

\section{TINJAUAN PUSTAKA}

Pada proses sheet metal forming plat akan ditekan untuk menghasilkan deformasi plastis, pada saat bending dihilangkan akan terjadi perubahan bentuk atau penyimpangan terhadap permukaan die yang digunakan untuk penekanan, hal ini disebabkan karena plat memiliki sifat elastis sehingga sebagian deformasi akan sedikit kembali ke titik tertentu. Penyim-pangan bentuk dan ukuran karena sifat elastisitas bahan ini dikenal dengan istilah springback, atau regangan elastis sisa pada daerah bending pada saat bending dihilangkan yang menyebabkan penyimpangan bentuk pada sheet metal terhadap bentuk die. Springback selalu terjadi pada sheet metal forming untuk itu perlu diperhatikan karena pengaruhnya sangat penting terhadap perubahan bentuk dan ukuran pada produk akhir yang dihasilkan. Springback dapat diamati pada proses bending dimana sudut bending pada saat bending dilepas(setelah terjadi springback) akan lebih kecil dibandingkan dengan sudut bending pada saat bending dilakukan pada plat, sedangkan jari-jari bending pada plat pada saat bending dilepas (setelah terjadi springback) lebih besar dibanding pada saat bending dilakukan. Springback tidak hanya terjadi pada plat tipis atau plat datar, tetapi juga terjadi pada bentuk poros pejal, kawat, batang dengan luas area tertentu, serta pada pipa. Pada prakteknya springback dapat dikurangi dengan memberikan bending lebih lama, beberapa trial sangat diperlukan untuk mengamati fenomena springback yang terjadi sehingga produk yang dihasilkan mempunyai bentuk dan ukuran yang sesuai dengan desain die. Hubungan antara besar sudut bending dengan radius bending dapat diukur pada panjang busur yang dihasilkan pada daerah yang mengalami bending menurut persamaan:

$$
\begin{aligned}
& W=\alpha_{b}\left(R_{b}+\frac{t}{2}\right) \\
& \text { atau }
\end{aligned}
$$

Panjang busur setelah springback 


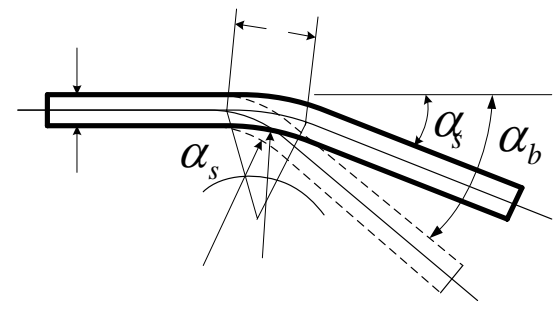

Gambar 2. Perubahan sudut plat pada teori prediksi springbac

$$
W=\alpha_{s}\left(R_{s}+\frac{t}{2}\right)
$$

Dimana:

$$
\begin{aligned}
\alpha_{b}= & \text { Sudut bending saat bending } \\
\alpha_{s}= & \text { Sudut bending setelah terjadi } \\
& \text { springback } \\
\mathrm{R}_{\mathrm{b}}= & \text { Radius bending saat bending } \\
\mathrm{R}_{\mathrm{s}}= & \text { Radius bending setelah terjadi } \\
& \text { springback } \\
\mathrm{t} \quad & \text { Ketebalan plat }
\end{aligned}
$$

Banyak peneliti memfokuskan penelitian mereka tentang springback pada defleksi (lendutan) pada plat bentuk lingkaran dan bentuk lembaran, Johnson dan Singh (1982) adalah orang yang petama melakukan eksperimen dengan menggunakan die silinder dan meneliti pengaruh radius tool, panjang dan tebal plat serta properti dari plat yang digunakan, dan banyak penelitian lain yang melakukan pendekatan analitis dengan menggunakan metode numerik. Pada dasarnya ada dua macam teori yang berkembang untuk memprediksi adanya springback yaitu discharge moment applied (momen yang hilang ) dan discharge of inplane force (gaya dalam bidang yang hilang), disini akan diperkenalkan secara singkat tentang dua teori yang berkembang tersebut.

a. Teori Momen Discharge

Menurut Lo's (1995) atau analisis Hosford dan Caddell's (1993) didapatkan persamaan:

$$
\frac{1}{R_{b}}-\frac{1}{R_{s}}=\frac{2 \sqrt{3 \sigma_{y}\left(1-v^{2}\right)}}{h . E} \ldots . .
$$

Dimana:

$$
\begin{aligned}
\mathrm{R}_{\mathrm{s}}= & \text { Radius akhir setelah } \\
& \text { mengalami springback } \\
\mathrm{Rb}= & \text { Radius selama bending } \\
& \text { berlangsung } \\
\mathrm{h}= & \text { Ketebalan plat } \\
\mathrm{E}= & \text { Modulus elastisitas } \\
\sigma_{y}= & \text { Tegangan bending } \\
v= & \text { Poisson ratio }
\end{aligned}
$$

Pada teori ini, springback yang terjadi pada plat didefinisikan sebagai berikut (Wu, Ying-Hui, 1996):

$$
\left(\alpha_{b}-\alpha_{s}\right) / \alpha_{b}=\frac{\Delta \alpha}{\alpha_{b}}=1-\frac{R_{b}}{R_{s}}=2 \sqrt{3\left(1-v^{2}\right)}\left(\frac{R}{h}\right)\left(\frac{\sigma_{y}}{E}\right)
$$

Dimana:

$$
\begin{aligned}
& \alpha_{b}=\text { Sudut selama bending } \\
& \alpha_{s}=\begin{array}{l}
\text { Sudut akhir setelah terjadi } \\
\text { springback }
\end{array}
\end{aligned}
$$

\section{b. Teori Force Discharge}

Berbeda dengan teori yang telah dikemukakan $\mathrm{Yu}$ et al (1984), untuk perlakuan stamping dan springback pada plat lingkaran yang dideformasi dengan die setengah lingkaran sesuai dengan analisa, springback pada plat berbentuk lingkaran dapat mendekati prediksi yang didasarkan pada distribusi gaya membran yang merupakan gabungan dengan metode singkat Calladine (Yu et al, 1984). Teori ini menjelaskan penurunan regangan elastis pada lingkaran yang menyebabkan sisi bagian luar akan bergerak atau bertambah lebar. Gaya membran tersebut didefinisikan sebagai beriku(t0) 


$$
N_{\alpha b}=-\sigma_{y} \cdot h
$$

Dimana:

$$
N_{\alpha b}=\text { Gaya pada membran. }
$$

Untuk plat dengan bentuk persegi maka gaya yang terjadi saat beban dihilangkan sebesar $2 \alpha_{y} . h / \sqrt{3}$ karena termasuk dalam regangan bidang.

Regangan yang terjadi pada plat bagian luar bending adalah:

$$
\varepsilon=2 \sigma_{y}\left(1-v^{2}\right) / \sqrt{3}
$$

Untuk plat bagian dalam bending akan mengalami tekanan atau pemendekan. Jika perbandingan $\sigma_{y}\left(1-v^{2}\right) / E$ sangat kecil maka akan didapatkan persamaan untuk memprediksi terjadinya springback (Wu, Ying-Hui, 1996).

$$
\frac{\Delta \alpha}{\alpha_{b}}=\frac{2 m\left(1-v^{2}\right) \sigma_{y} \cos \alpha_{b}}{\sqrt{3 E\left(1-\cos \alpha_{b}\right)}} \ldots . .
$$

Dimana:

\section{HASIL DAN PEMBAHASAN}

\section{Deformasi Ketebalan Elemen}

$m=$ faktor radius, sesuai dengan $\mathrm{Yu}$
et al (1984) sebesar $9 / 4$

$\Delta \alpha=\alpha_{b}-\alpha_{s}$ adalah perubahan sudut mengalami bending dan sudut akhir setelah terjadi springback.

\section{METODE PENELITIAN}

Metode ini dimulai dengan melakukan survei dan studi pustaka. Kemudian dilakukan pemisahan dan menconvert komponen die dari file nastran benckmark II numisheet 2005 menggunakan MSC. Patran untuk selanjutnya dilakukan simulasi numerik menggunakan ABAQUS V.64 PR.11 yang diharapkan memperoleh hasil yang dinginkan. Bila hasil tidak diperoleh maka dilakukan editing model dengan mengurangi jumlah elemen dan penambahan signifikan pada velocity. Editing model tersebut dilakukan untuk menyesuaikan dengan kemampuan fasilitas komputer dalam melakukan analisis model.

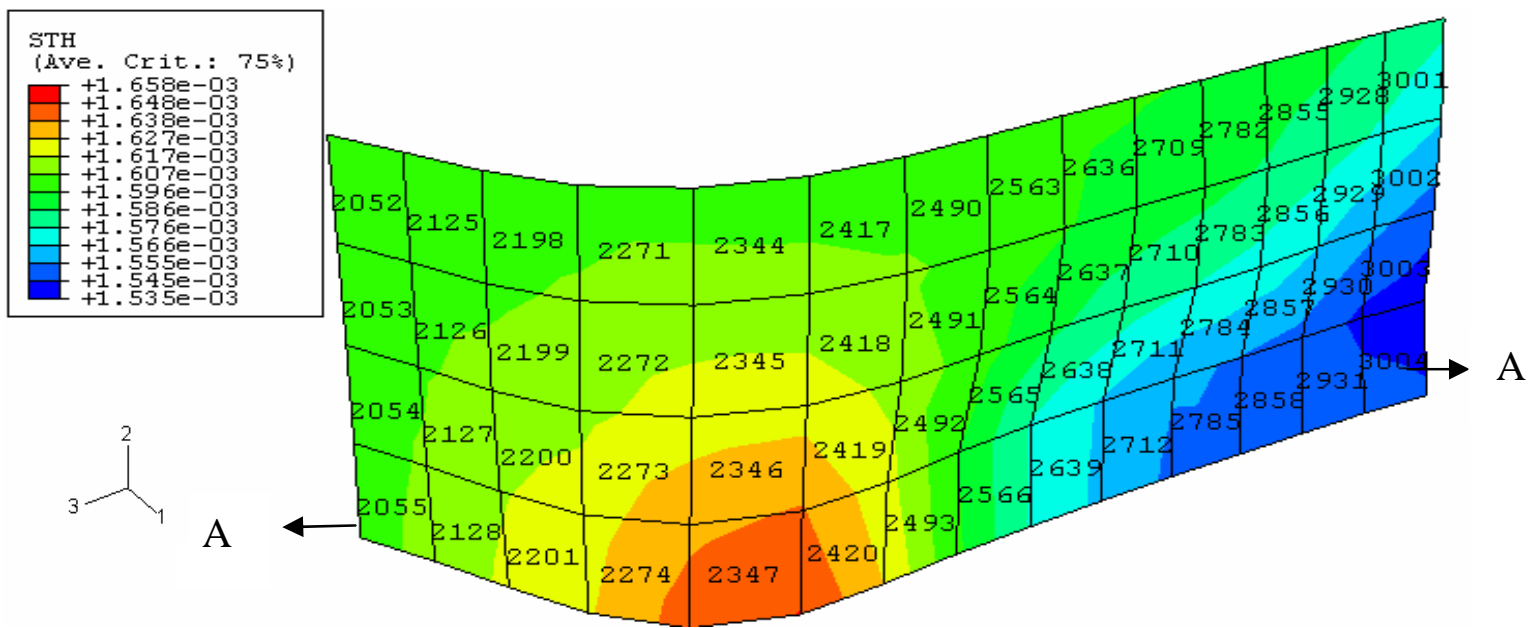

(a) 


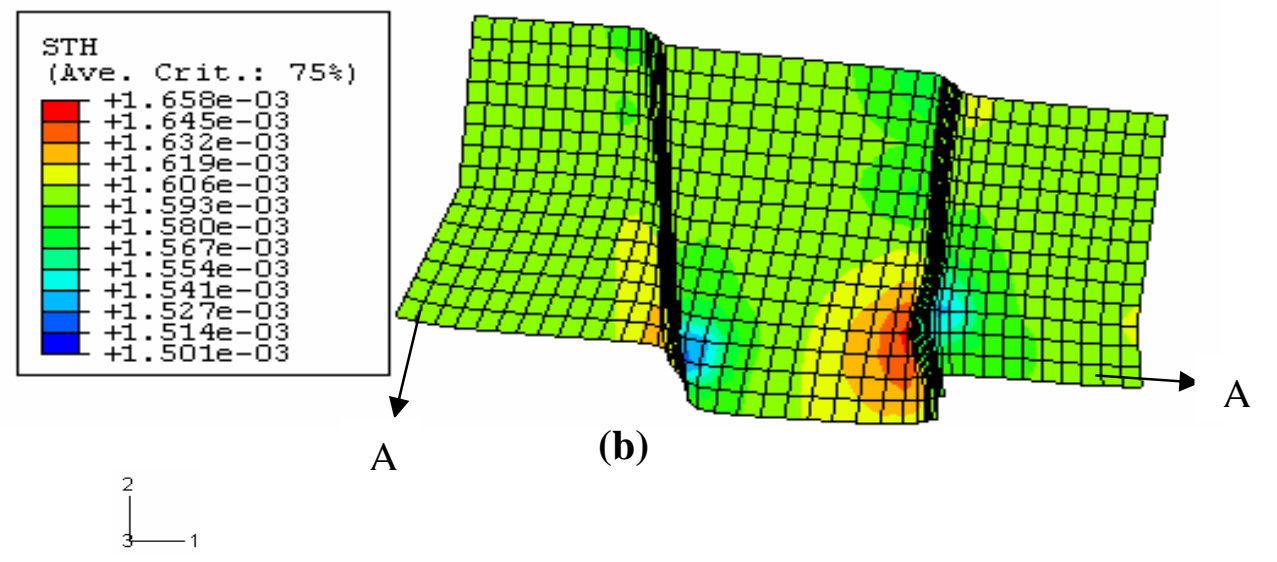

Gambar 3. (a) Fully loaded A-A, (b) Sumbu 1,2 untuk fully loaded A-A

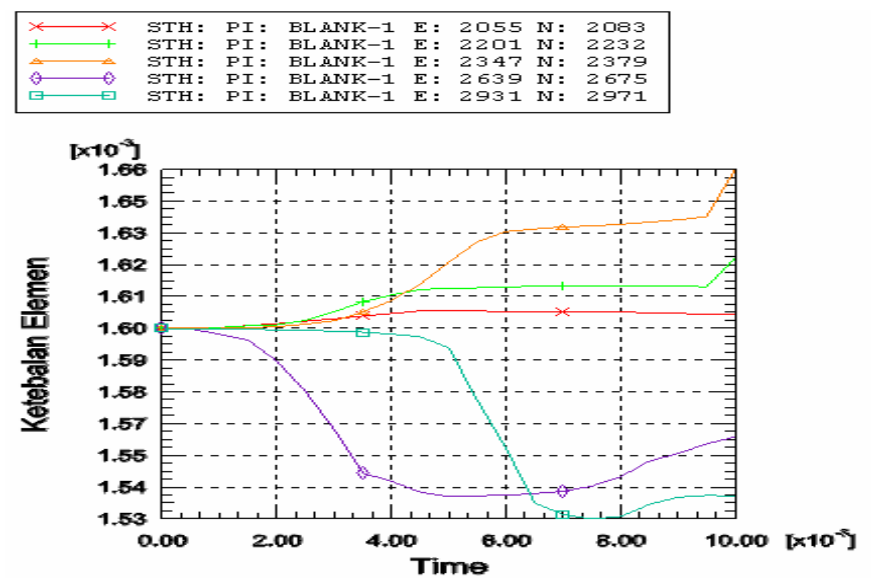

Gambar 4. Diagram deformasi ketebalan pada fully loaded A-A

Terjadi deformasi ketebalan elemen pada fully loaded A-A. Penebalan dan penipisan elemen diwakili oleh kontur warna berbeda yang ditunjukkan pada gambar 3 . Penebalan pada elemen 2347 terjadi karena posisi elemen ini terletak pada alur melengkung yang diperlihatkan pada gambar 3.(b). Penebalan ini terjadi karena adanya strain negatif pada proses formed ke arah sumbu 3 dimana terjadi konsentrasi displacement ke arah elemen ini. Sedangkan penipisan elemen tampak terjadi pada elemen 2931. Hal ini disebabkan oleh adanya strain positif pada proses formed dimana displacement cenderung keluar dari elemen ini.

Diagram deformasi ketebalan ditunjukkan pada gambar 4 yang merupakan seleksi elemen yang diambil dari fully loaded A-A yang menampilkan kontur warna berbeda. Meskipun terjadi penipisan elemen pada fully loaded A-A tetapi tidak menunjukkan adanya sobek ataupun mengkerut akibat dari adanya penebalan elemen. Hal ini menginformasikan bahwa simulasi ini masih menghasilkan blank deformable yang halus atau baik. 


\section{Distribusi Energi}

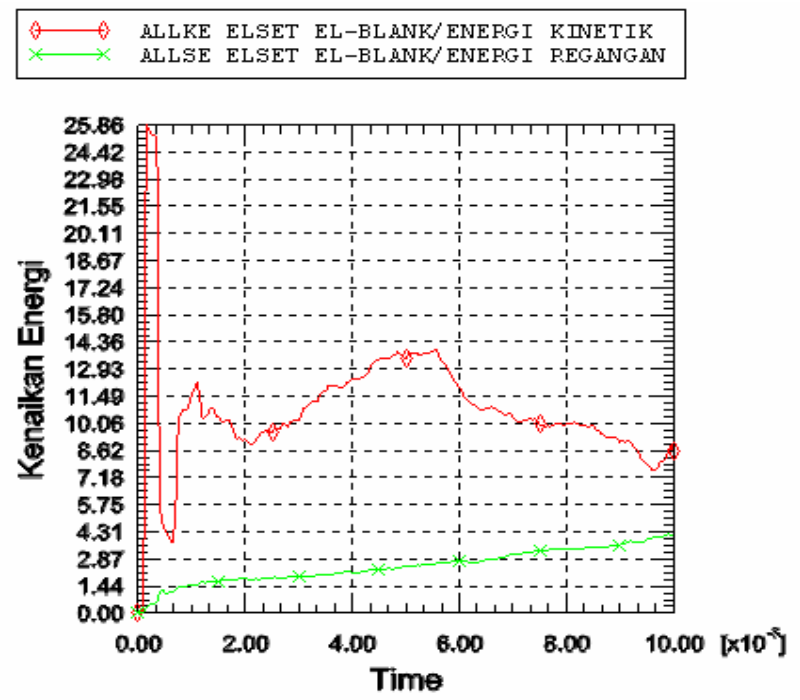

Gambar 5. Grafik hubungan energi kinetik, energi regangan dengan time

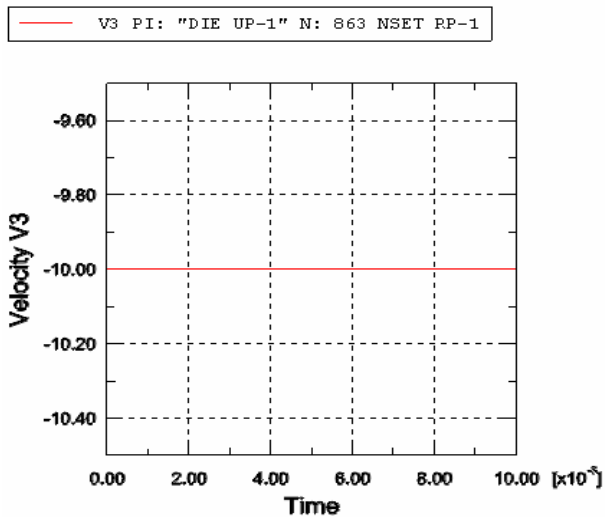

Gambar 6. Grafik hubungan velocity dengan time

Pada grafik gambar 5 menunjukkan energi kinetik yang lebih besar dari energi regangan. Energi kinetik yang berlebihan artinya memperlihatkan bahwa tabrakan yang terjadi antara die up dengan material deformable pada awal proses sheet metal semakin besar dimana hal ini dapat menyebabkan terjadinya kerusakan pada elemen atau bahkan menyebabkan error pada proses simulasi. Hubungan antara grafik gambar 5 dengan grafik gambar 6 yaitu energi kinetik harus lebih kecil daripada energi regangan untuk menghasilkan simulasi yang aman. Untuk memperkecil energi kinetik, dapat dilakukan pengurangan velocity sehingga simulasi dapat diaplikasikan pada industri manufaktur dalam proses sheet metal forming sebagai suatu perhitungan numerik yang aman.

Pada simulasi ini tidak dilakukan langkah perencanaan untuk simulasi yang aman dengan menggunakan velocity yang kecil yang lebih aplikatif untuk industri sheet metal forming. Hal ini dikarenakan keterbatasan fasilitas komputer untuk menganalisa model. 


\section{Fenomena Springback}

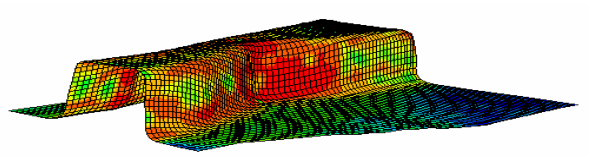

a

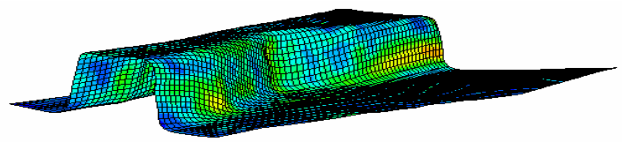

b

Gambar 7. (a) Frame 20 step formed (b) Frame 20 step springback

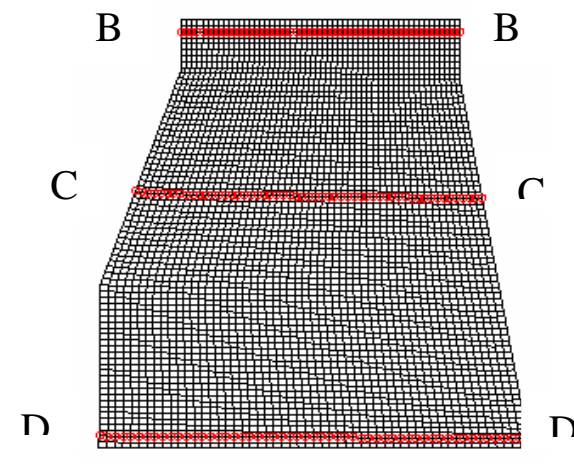

a

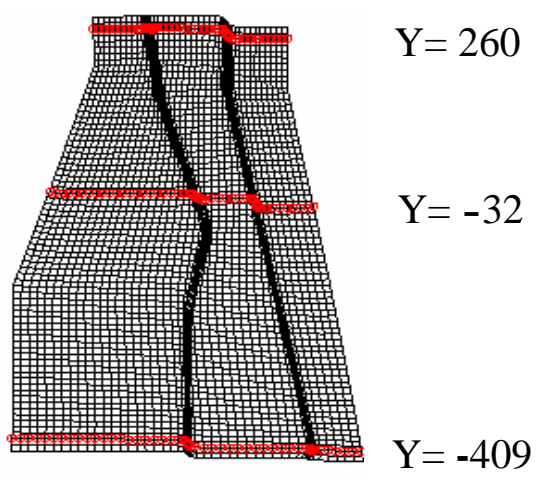

b

Gambar 8. (a) Fully loaded B-B, C-C, D-D (b) Posisi bıank setelah mengalami stamping

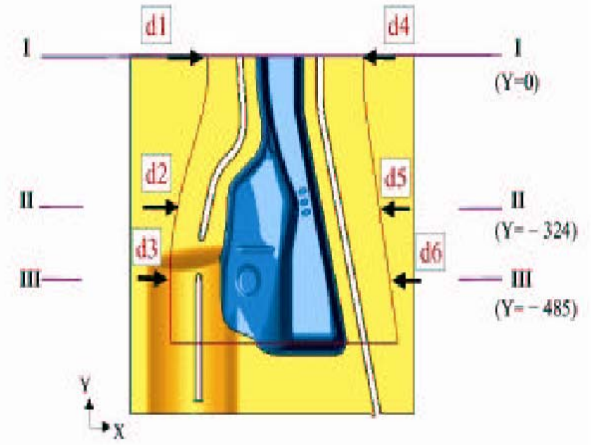

Gambar 9. Koordinat y untuk fully loaded pada file asli

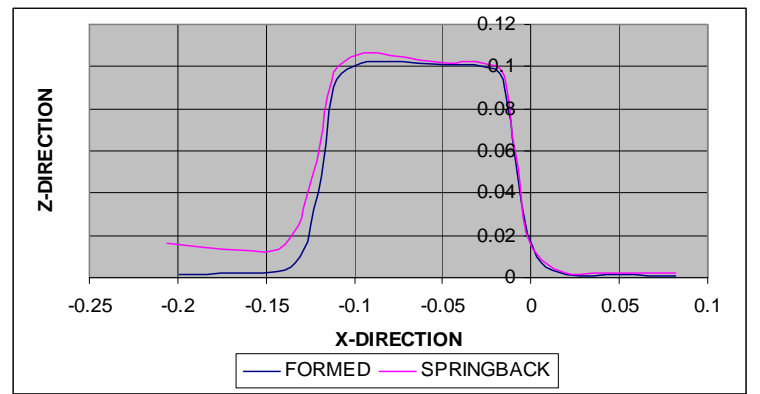

Gambar 10. Grafik fenomena springback fully loaded B-B (Y = $260 \mathrm{~mm})$
Gambar 7 frame 20 step formed dan frame 20 step springback merupakan referensi yang digunakan untuk memvisualisasi twisting yang terjadi, sedangkan gambar 8 merupakan fully loaded yang dipilih untuk menampilkan koordinat frame gambar 7.
Pada modeling tersebut terjadi perubahan koordinat y dari file aslinya pada fully loaded di atas. Melakukan modeling artinya hanya melakukan pendekatan yang memberikan gambaran bahwa model yang dibuat adalah mirip dengan file aslinya. Koordinat y pada fully loaded file aslinya ditunjukkan pada gambar 9 . 


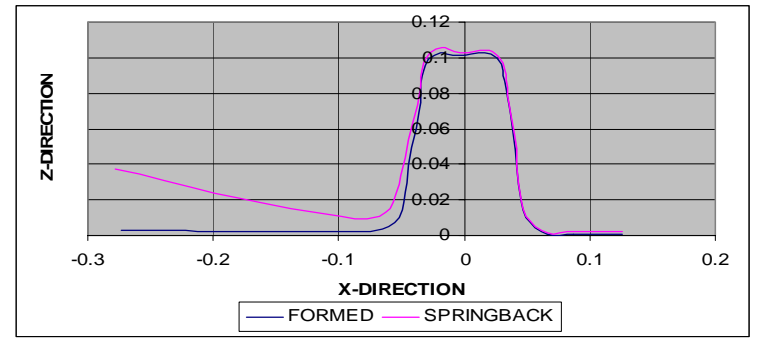

Gambar 11. Grafik fenomena spring back fully loaded C-C (Y = -32 mm)

\section{KESIMPULAN}

Dari penelitian ini dapat disimpulkan beberapa hal:

1. Pada simulasi ini menunjukkan bahwa pada deformasi ketebalan elemen tidak memperlihatkan adanya robek akibat terjadinya penipisan elemen dan mengkerut akibat adanya penebalan elemen. Hal ini menginformasikan bahwa simulasi ini masih menghasilkan blank deformable yang halus atau baik.

2. Energi kinetik berlebih dapat menyebabkan terjadinya kerusakan

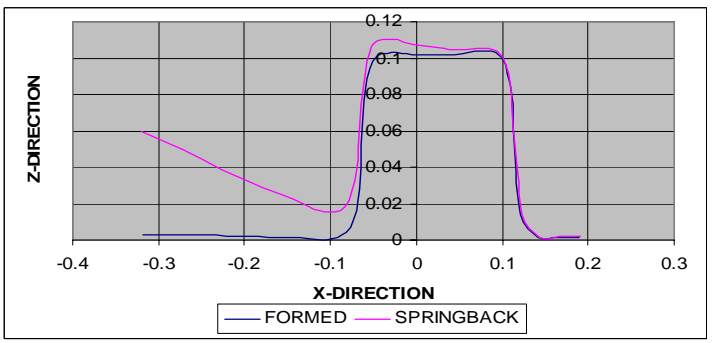

Gambar 12. Grafik fenomena spring back fully loaded D-D (Y = -409 mm)

pada elemen deformable atau bahkan menyebabkan error pada simulasi, untuk itu perlu dilakukan pengurangan velocity.

3. Springback dapat dikurangi dengan memberikan pembebanan lebih lama, beberapa trial sangat diperlukan untuk mengamati fenomena springback yang terjadi sehingga produk yang dihasilkan mempunyai bentuk dan ukuran yang sesuai dengan desain die.

\section{DAFTAR PUSTAKA}

Cook, R. D., 1981, Concepts And Aplications Of Finite Element Analysis, John Wiley \& Sons, inc, Canada.

Makinouchi, A., 1996, Sheet Metal Forming in Industri. Journal of Material Processing Technology, V.60, hal. 19-26.

Marciniak, Z., et.al., 2002, Mechanics Of Sheet Metal Forming, Butterworth-Heinemann, London

Singer, F.L., dan Andrew Pytel, 1995, Ilmu Kekuatan Bahan (Teori Kokoh-Strength of Material), alih bahasa Darwin Sebayang, Edisi II, Erlangga, Jakarta.

Siswanto, W. A., 2001, Single Stage Sheet Metal Forming Simulation Using ABAQUS Coupled Explicit-Implicit, Benchmark Problem Square Cup Deep Drawing in Numisheet 1993. 